\title{
Road Maintenance in Africa: Approaches and Perspectives
}

\author{
Mostafa Hassan M \\ Sustainable Roads, Urban and Transportation (SURT) research group, Department of Civil Engineering, Central University of \\ Technology, South Africa
}

\begin{abstract}
In Africa, roads are the dominant mode of passenger and freight transport, for which the need is growing rapidly. It is noticeable that most of the African countries do not do enough to ensure the sustainability of road infrastructure as it has been widely reported that roads are affected, to varying degrees, by premature deterioration. Most of the African countries have adopted institutional reforms, notably entailing the creation of road funds and road agencies, and made significant progress on road maintenance. However, many challenges remain to be addressed in all of them to ensure appropriate maintenance. Although spending on road maintenance has increased over time in all African countries it remains insufficient to cover the needs. Poorly maintained roads constrain mobility, significantly raise vehicle operating costs, increase accident rates and their associated human and property costs, and aggravate isolation, poverty, poor health, and illiteracy in rural communities. This paper focuses, in particular, on road maintenance in some African countries considering types of road maintenance and the different approaches aiming at a comparison to reflect on similarities and differences.
\end{abstract}

\section{Introduction}

After independence, some African countries inherited road networks which were developed for the sake of colonial manipulation and military ascendancy [1]. These networks were developed and maintained to a certain extent because of the limited availability of funds. Road density, although low in general, started to increase and this increase was vividly noticed in some countries e.g. Madagascar, Malawi, Mozambique, and Niger [2]. Generally, road conditions have improved in most African countries in recent years as governments have strived to increase the density of their road networks. Remarkable progress has been made in founding organizations to manage and maintain African roads. Nonetheless, only one in three rural Africans have access to an all-season road and in cities, road construction has not kept pace with urbanization. In many countries, road maintenance remains inadequate. This is, mainly, because of lack of proper funding. Most African countries have followed a steady path in the roads sector, with the focus on improving the availability of funds for road maintenance and the capability to execute public works. One of such initiatives is the Sub-Saharan African Transport Policy Program. The main focus has been on the creation or enhancement of road funds which provide ring-fenced revenues for road maintenance, based on a user charge concept expressed through fuel levies. Another area of interest has been in the formation of independent Road Agencies in most of the African countries. This is all to achieve the main target of executing and maintaining good roads. One example is The South African National Road Agency Ltd (SANRAL) in South Africa. This paper looks at the different maintenance schemes and trends in some of the African countries. For the sake of length of the paper, only one country from each region in Africa is presented. The aim is to investigate the similarities and differences in the African maintenance perspectives.

\section{East African Countries: Ethiopia Approach}

Ethiopia is classified as am underdeveloped country and over the years has increased the size of the road network due to the approach to road maintenance and rehabilitation. Ethiopian road network has increased approximately from $6,400 \mathrm{~km}$ in $1951,46,812 \mathrm{~km}$ in 2010 and in 2015 to $85,966 \mathrm{~km}$ [3]. Earlier, a lack of a comprehensive approach to maintenance in Ethiopia has led to an accumulation of backlog of road maintenance. However, with the reformation of the building blocks of road management initiative; which are: management, ownership, financing and responsibility; Ethiopia is gradually coming out of the shadow of poor road network [4].

The increase in road networks in Ethiopia resulted from the controls and regulations put in place by the RTA and the attention given by the Ethiopian government, as this was an endeavor taken by the government to help improve the country's economy. RTA was established in the 1967 to oversee matters related to roads and vehicles using roads in Ethiopia [5]. RTA's vision statement is; "...ensure the provision of a modern, integrated and safe

* Corresponding author email: $\underline{\text { mmostafa@cut.ac.za }}$ 
road transport services to meet the needs of all the communities for strong and unitary economic and political system in Ethiopia". Therefore, RTA sees maintenance as the core in achieving this vision.

It is known that the road management aspect is always hampered by funding, but in the case of Ethiopia, this was resolved by the introduction of a road fund. The road fund in Ethiopia was established in 1997, after great consideration to resolve the maintenance issues. The road fund in Ethiopia was developed on the fee-for-service principle. However, to a great extent this reformation has been encouraging and thus, Ethiopia was classified as a good performer in terms of road maintenance. Overall, the maintenance culture in Ethiopia has greatly increased over the years, as a result of proper funding through the road fund model and the reformation made in the road management sector.

\section{West African Countries: Nigeria Approach}

Nigeria is one of the fastest growing economies in Africa and has the largest road network in West Africa and the second largest in Sub-Saharan Africa. The road network in Nigeria is estimated to be almost $200,000 \mathrm{~km}$ in length, however, the performance of the Nigerian road sector has not been satisfactory. Thus, this has contributed negatively and retards the economic growth in the country [6]. Although, a huge sum of money has been directed towards road development in Nigeria, due to increase in traffic volumes; roads are still not in good condition.

Federal Road Maintenance Agency (FERMA) in Nigeria is saddled with the maintenance issues at the federal level while the state's ministries handle the state and further helps with the local government roads [7]. Nevertheless, the financial and technical requirements for effective maintenance, rehabilitation and reconstruction are so staggering that the rate of maintenance could not match the deterioration [2]. Thus, there is a need to look into the maintenance schemes adopted by Nigerian's road agency which brought about the ineffectiveness. Unlike Ethiopia, despite some maintenance activities performed in Nigeria, routine and special maintenance are still behind schedule; this is as a result of roads not begin properly constructed and inadequate funding for maintenance activities. Overall, maintenance problems in Nigeria can be attributed to the lack of proper or consistent funding. Adding up to that is the issue of the method of contracting out road maintenance work, which FERMA and State ministries still rely on traditional methods; e.g. in-house teams; thus results in failure. However, privatization of maintenance work with performance-based contracts is considered as a cost-effective alternative.

\section{Central African Countries: Angola Approach}

Angola's road network consists of $7,777 \mathrm{~km}$ paved, $28,018 \mathrm{~km}$ gravel, and $36,528 \mathrm{~km}$ earth roads, totaling $72,323 \mathrm{~km}$. Although, Government currently spends around 4.3 billion US dollar per year to rebuild the infrastructure, which is the equivalent to $14 \%$ of its GDP. Yet, there is still a lot of work to do to pull Angola from the shadows of war. Instituto Nacional de Estradas de Angola (INEA) is responsible for planning and managing Angola's national highway and between 2008 and 2009, a total of $5,600 \mathrm{~km}$ of roads were reconstructed.

In addition, much of the road network has received little or no maintenance, as many roads are located in the former war zone and have little or no traffic. Thus, INEA has limited knowledge of the true condition of many roads and of the likely rehabilitation costs. Therefore, it is necessary for INEA to improve data collection in order to understand the present condition of roads and bridges and the nature and volume of road traffic to be able to better plan highway and roads development and supply information to the private sector. The Angolan government has given priority to the rehabilitation of the national road network. However, at present, financing road rehabilitation and maintenance in Angola is directly dependent on the state budget as the road fund is not yet in operation [8].

The concept of a Road Fund (RF) was proposed to have independent management with the participation of different stakeholders, constituting the main source of revenue to INEA. Nevertheless, until the road user charges (tolls levies) are reviewed in Angola, the RF will be unable to serve its intended purpose to fund road rehabilitation and maintenance. Thus, INEA is proposing a strong increase, particularly in fuel and circulation taxes, with all proceeds reverting directly to the RF [8]. Overall, progress to complete Angolan road infrastructure is likely to take decades, but substantial efforts are already being made in the right direction.

\section{North African Countries: Egypt Approach}

The National Roads project is the largest Egyptian infrastructure project, with an adequate investment $(0.7 \%$ of the GDP). However, road maintenance is said to be neglected, as it constitutes only $0.15 \%$ of the Egypt's GDP; this is small in comparison with that of Ecuador $(0.23 \%)$, Morocco $(0.24 \%)$ and $0.45 \%$ for Ukraine [9]. This negligence in-turn results in road accidents and consequently accounted for $1.5 \%$ loss of the GDP or even more. Since 2001, the Egyptian government has however increased the funding allocated to road and railway to improve transportation sector. Further, in 2009 an economic stimulus package increased the spending, putting transport infrastructure catch-up high on the political agenda. Yet, $75 \%$ of the roads need maintenance; as nearly 700 bridges out of the 1,706 bridges in Egypt are on the verge of collapse due to insufficient maintenance and this has contributed adversely to the domestic transport system, as well as the international transport system.

In harnessing this situation, the Government of Egypt set up an organization for the development and maintenance of roads. General Authority of Roads, Bridges and Land Transport (GARBLT) is in-charge of not 
only maintenance of roads in Egypt, but also its development. The organisation's mission is focussed on safety, efficiency and a well-managed road network and has jurisdiction over 23,000 km of the road network. Recently GARBLT started a program for bridge maintenance/management and repair. However, the program has not been as successful, due to a lack of human resources in terms of technical know-how and equipment for appropriate inspection and evaluation of bridges. In general, the state of maintenance of the road network in Egypt is still a dilemma.

Overall, considering the state of the road network in Egypt at present, it needs rehabilitation rather than maintenance. However, one of the major stumbling blocks is funding. Through GARBLT's initiative, funds are generated through tolls, advertisement, fines on overloaded trucks etc. However, this structure changed with a new regime taking over in Egypt since 2013. This change resulted in major projects running fast to expand the motorways under the supervision of the military. No data is available on these new projects, the new structure, or the maintenance plans.

\section{Southern African Countries: South Africa Approach}

South Africa has the longest total road network in Africa and the 10th longest in the world, similarly the 18th longest paved road network in the world. The total length is approximately $746,978 \mathrm{~km}$, with only $21 \%$ paved $(153,719 \mathrm{~km})$. However, despite the fact that South Africa is economically foremost on the continent, it has roads in a fair to poor road condition of about $38 \%$. Some of these conditions are due to a lapse in maintenance actives, although it is better when compared with that of other African countries [10].

Road maintenance in South Africa is handled by SANRAL; the creation of SANRAL in 1998 was a result of the government commitment towards transforming public sector [11]. SANRAL has jurisdiction over $92 \%$ of the national road network, of which $81 \%$ are non-toll and the remaining tolled (over 19,000 km). Further, the remaining $8 \%$ of the total road network is also tolled and is developed and managed by private bodies. Management by these private bodies is still overseen by SANRAL based on concession contract agreements. The concession contract duration is thirty years, after which the road is handed over to SANRAL. The non-toll road in South Africa are funded directly by tax revenues generated by the national government, but as a result of the insufficient funding from the government, in 1995, the toll road was introduced to support the development and maintenance of roads in South Africa. These are maintained with toll revenues and capital market borrowing [11]. Overall, while toll road conceding is rare in Africa, South Africa in the Sub-Sahara region has the most, which is approximately $0.1 \%$.

It can be said that SANRAL is very close to achieving its aim and was categorised as a top performer alongside with Namibia. Yet, South Africa has a road maintenance funding backlog of approximately 80-149 billion Rand [12]. Apart from funding, SANRAL is getting it right with the strategies of maintenance such as; routine, periodic and special (urgent) maintenance which are in place. Only the municipal roads are not well managed, this results from poor data collection (only 4\%) of the present conditions available, and thus municipality coordination and responsibility are confused. Nonetheless, the manner of contracting maintenance work, which is performancebased, has greatly contributed to the success achieved in South Africa [13].

\section{Discussion on African Road Maintenance}

Basically, the types of maintenance activities carried out are more of the same in most African countries, however, the approach differs. Nevertheless, the importance of road maintenance cannot be overemphasized because of its enormous contribution to the nation's regional integration and economic growth, social development, effective public administration and security. Additionally, maintenance sustains the quality and safety of the road condition close to the original design, and thus, minimizes the road user costs, accident rate, poverty level and even its reconstruction cost. However, delay in maintenance is tantamount to its reconstruction as it results in high direct and indirect costs. Yet, Burningham and Stankevich [14] reported that many countries, not only in Africa, usually spend just about $20-50 \%$ of the actual amount for road maintenance. However, according to World Bank reports, neglecting maintenance at any stage may result in spending 3 times or more of maintenance costs.

The overall comparison between the covered countries is presented in table 1 . This table shows clearly that only Ethiopia has a running road funding model independent of the governmental support. However, the case of South Africa shows good progress in this regard while all other countries are dependent on the governmental budget. This budget, in all cases, is constraint by the development needs of the African countries. Therefore, maintenance always comes last on the priority list of these governments. The way forward is to develop different road funding models as per the special needs and cultures of the African countries. Moreover, it is evident that maintenance culture is not widely propagated in Africa as most countries do not give it the proper attention especially in countries with a vast population.

Focusing on the problems related to maintenance, it is obvious that these problems are the same everywhere as lack of funding and deficiency of data and information are the main problems. It is of utmost importance to the African countries to have a database connected to all countries to help in minimizing the costs connected to road maintenance and also construction. 
Table 1 Comparison Between The Maintenance Perspectives of the Studied African Countries

\begin{tabular}{|c|c|c|c|}
\hline Country & Road fund & Maintenance culture & Main problems \\
\hline Ethiopia & Road fund model & Good & Insufficient fund \\
\hline Nigeria & Annual fund from the government & Very poor & $\begin{array}{l}\text { Lack of funds } \\
\text { Lack of proper } \\
\text { administration }\end{array}$ \\
\hline Angola & $\begin{array}{l}\text { Annual fund from the government } \\
\qquad+\end{array}$ & Poor & $\begin{array}{c}\text { Lack of information } \\
\text { Lack of fund }\end{array}$ \\
\hline & Road fund model (Partial) & & $\begin{array}{l}\text { Need to develop } \\
\text { network }\end{array}$ \\
\hline Egypt & Annual fund from the government & Very poor & $\begin{array}{c}\text { Lack of fund } \\
\text { Lack of information }\end{array}$ \\
\hline South Africa & $\begin{array}{c}\text { Annual fund from the government } \\
\qquad+\end{array}$ & Fair & $\begin{array}{c}\text { Poor data at } \\
\text { municipalities }\end{array}$ \\
\hline
\end{tabular}

\section{Conclusions}

Considering the current situation in most African countries, to a great extent, the level of road maintenance's effort can be said to be comparatively high to the overall economic size, yet these efforts remain little when compared with those of other developing countries around the world. A considerable percentage of the African countries can be said to have gotten it right on the aspect of road ownership and responsibility and creation of road management agencies, yet, the financing aspects still remain lacking, as most still depends directly on the government funding which is absolutely insufficient. Generally, to a large extent the road agencies know what to (with regards to maintenances) but the funding is always handicapping them.

As mentioned in the case of Ethiopia, the giant step in the establishment of the road fund has been a great contribution to the success recorded. While, Egypt, Nigeria and South Africa have established road agencies, the implementation of a road fund is not yet in place. However, the situation of South Africa is far better than that of Nigeria, because of the implementation of toll roads, which is one of the largest in the continent. Toll roads can still be considered to be equivalent to road fund, as this effort in South Africa is coupled with the private partnership concept which thus place South Africa above in the continent.

In conclusion, there is a need for African countries to look into the following as a way-out of the current road maintenance predicament:

- Incorporation of maintenance into road project and sector strategies

- Consideration of establishment the road fund concept

- Expansion of toll roads network

- Investment in other forms of transportation such as rail transport and integrated public transport system to reduce congestion of the roads
- Consideration of performance-based contract for contracting out maintenance work

- Involvement of public-private partnership concession concept

\section{References}

1. Fage, J D A History of Africa 2002 Taylor and Francis, fourth edition.

2. Foster, V and Briceno-Garmendia, C 2010 Africa's Infrastructure: A Time for Transformation. The International Bank for Reconstruction and Development / the World Bank.

3. The World Bank Ethiopia Road Sector Support Project 2015 Report No PAD700.

4. Road Sector Development Program 2001 Road Fund in Ethiopia: From Inception to Realization Mid - Term Review Meeting of RSDP, 6-7 February, 2001.

5. RTA: Ethiopian road transport authority 2014 [Online] available at http://www.rta.gov.et/ [Accessed 24 April, 2015].

6. The United Nations 2014 Economic Development in Africa: catalysing Investment Growth in Africa eISBN 978-92-1-056677-3.

7. Federal Roads Maintenance Agency (FERMA) 2014 Federal Roads Maintenance Agency (FERMA). [Online] Available at: http://www.ferma.gov.ng [Accessed April 2014].

8. The World Bank 2005 Private Solutions for Infrastructure in Angola, the World Bank, Washington, DC.

9. MENA-OECD Initiative 2010 Infrastructure: Business Climate Development Strategy: Phase 1 Policy Assessment: Egypt.

10. Jones, D Paige-Green, P and Sadzik, E Development of Guidelines for Unsealed Road Assessment 2003 Transportation Research Record. 1819. DOI: 
10.3141/1819a-42.

11. SANRAL (2014). 2014 Annual Report. [Online]. Available at: http://www.nra.co.za/content/SANRAL_Annual_Re port 2014 PRESS 149 15.pdf [Accessed 25 April, 2015].

12. Krygsman, S. (2011). Road maintenance: Toll roads part of a package of solutions. [Online]. Available at: http://blogs.sun.ac.za/news/2011/12/23/ [Accessed July 2015].

13. Goitom, H. (2014). National Funding of Road Infrastructure: South Africa, [online]. Available at: http://www.loc.gov/law/help/infrastructure-

funding/southafrica.php\#skip_menu [Accessed June 2015].

14. Burningham, S and Stankevich, N 2005 Why road maintenance is important and how to get it done, Transport Notes, The World Bank, Washington, DC. 